\title{
Comparison of Common Deep Drawing Steel Sheets in terms of Blank Holder Force and Friction Conditions
}

\author{
Özgür Özdilli ${ }^{1}$, M. Emin Erdin ${ }^{2}$
}

${ }^{1}$ Department of Machine and Metal Technology, Hitit University, Çorum, 19169, Turkey
${ }^{2}$ Department of Mechanical Engineering, Hitit University, Çorum, 19169, Turkey

\begin{abstract}
In this study, it is aimed to make comparison of four different steel sheet materials that are widely used in deep drawing applications by taking blank holder force and friction conditions into account. Comparison is made between a standard steel which is generally used in white goods manufacturing (DC01), an ultralow carbon steel (DC04), a deep drawing steel suitable for cold forming (DD13) and an extra deep drawing steel resistant to ageing (DD14), which are preferred when manufacturing a part by deep drawing, if there is not any special material requirements. The purpose of this study is to make selection between these mentioned materials easier. Simufact.forming, a plastic deformation analysis software based on finite element method, and material database of the software was used in the conducted analyzes. Various blank holder forces were applied and friction conditions were changed for each material. By investigating obtained results, it was seen that there is a significant difference between deep drawing behavior of these materials and DD14 has high deep drawability even under high blank holder forces with low energy. Moreover, it was observed that friction conditions have a significant influence on effectiveness of deep drawing process.
\end{abstract}

Keywords: Deep Drawing, Steel Sheet, Drawing Ratio, Blank Holder Force, Coefficient of Friction, Finite Element Analysis.

\section{* Corresponding author \\ Özgür Özdilli}

ozgurozdilli@hitit.edu.tr

Adress: Department of Machine and Metal Technology, Hitit University, Çorum, 19169, Turkey

Tel:+903642230800

Fax: +903642230804

Manuscript Received 25.09.2018

Revised 27.09.2018

Accepted 29.09.2018

Doi:10.30939/ijastech..463629

\section{Introduction}

Deep drawing is a widely used sheet metal forming method (Figure 1). Many products such as automobile, train, aircraft and machine body panels; pressure vessels; white goods; kitchen sinks; cookware; medical containers; beverage cans and vehicle rims are manufactured with the deep drawing process [1]. Due to the non-linear plastic deformation characteristic of the deep drawing and the nonhomogeneous material flow during the process, it is very difficult to control the efficiency of the process. The desired deep draw ratio may not be achieved unless the deep drawing parameters are selected appropriately. In addition, deep drawing defects such as tearing, wrinkling and earing can be encountered [2]. In various studies, the effects of different blank holder forces on the occurrence of wrinkling and tearing on sheet metal have been investigated experimentally [2-4].

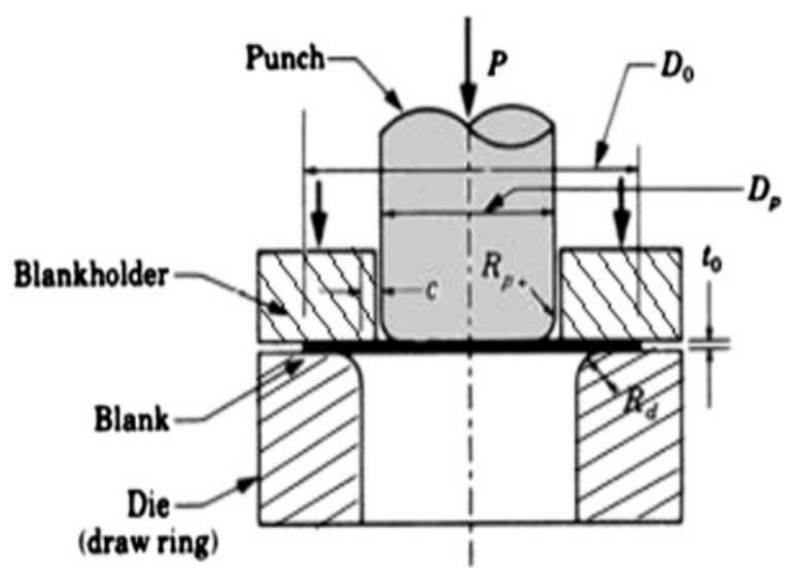

Fig. 1. Circular cup deep drawing [5]. 
Yıldız and Kirli (2004) have emphasized that it is more economical to find solutions to problems encountered in deep drawing processes with numerical programs. In this context, they have investigated the required activities to predict the results of design changes before the manufacturing of the molds to eliminate the shape defects such as tearing, wrinkling and earing during the deformation of steel sheet material for complex geometries. For this purpose, they have used different deep drawing parameters to observe the effects of these parameters on tearing, wrinkling and earing defects [6].

Mori and Tjusi have performed a study (2007) by using cylindrical and squarish deep drawing molds to measure the effects of die radius, friction values and blank holder force. In the study, six lubricants of four different types and different blank holder forces were used. Obtained results were compared at different temperature conditions [7].

Browne and Hillery (2003) experimentally investigated the effects of important parameters for process performance, namely punch and blankholder force, lubricant type and application region in their study in which they stated that it is critical to select deep drawing process parameters correctly, and determined conditions which make product's thickness distribution the most homogeneous [8].

Admanabhan et al. (2008) aimed to improve the thickness distribution and decrease the thinning tendency of the deformed product in the optimization study they performed for determination of appropriate blank holder force in deep drawing. They have determined the appropriate blank holder force according to wrinkling degree of the deep drawing specimen and applied the obtained blank holder force to wrinkling zones on the product. The obtained results were compared with the results of the experimental studies performed with constant blank holder force [9].

Some of the factors affecting the deep drawing process were analyzed using finite element analysis procedure in the study performed by Gök [10]. By this means, it has been shown that the factors affecting the deep drawing process can be controlled in the design stage and the cost can be reduced.

When the studies on the blank holder force are examined, it is seen that the blank holder force directly affects the forming process. Low blank holder force causes wrinkles on the deep drawn product, while high deep drawing force causes tearing on the product due to increasing friction force between the sheet material and the molds [11-12].
Demirci et al. (2008) have investigated the effects of constant blank holder force on the part thickness distribution. In the study, the effects of various blank holder forces on the deep drawn cups were observed via finite element analysis. The results obtained from finite element analyzes were compared with the experimental results. As a result of the theoretical and experimental studies, it was emphasized that the blank holder force should be determined appropriately in order to eliminate wrinkling of the sheet material and not to exceed the limiting drawing ratio (LDR). Nowadays, deep drawing is widely used in the industry, but its use in industry is based on experimental methods which is a very expensive and time-consuming approach [13].

Simulation programs based on the finite element method eliminate these problems. Thus, finite element software are widely being used in plastic forming applications each passing day, especially in deep drawing processes. These software can reflect the fact as good as possible depending on the verisimilitudinousness of the entered data to the physical conditions. The most important of these data for deep drawing operations are material properties, die geometry, blank holder force and friction values. Unfortunately, it is not always possible to test different material types for a piece to be produced in industry. With this study, it will be able to obtain information about the results of deep drawing of the various types of steel sheet materials which are frequently used in deep drawing processes in different blank holder force and friction values.

In this study; the stress, punch stroke, sheet thickness variation, molding force and deformation energy values have been compared by analyzing the steel materials used in deep drawing process in two different blank holder pressure and friction coefficient values via finite element simulation.

Punch stroke (h) which also expresses the obtained height of deep drawn product is an important output of the deep drawing process. Total energy $\left(E_{t}\right)$, which is calculated as follows, expresses the work made during the deep drawing process,

$$
E_{t}=\int_{0}^{h_{\max }} F_{d d} d h
$$

where $F_{d d}$ is the deep drawing force $[\mathrm{kN}]$. 


\section{Material and Method}

The study was carried out with circular steel specimens having $150 \mathrm{~mm}$ original diameter and $1 \mathrm{~mm}$ thickness. Finite element analyzes were realized on commonly used deep drawing steel materials having different mechanical properties and chemical compositions, which are found in the material database of Simufact.forming plastic deformation software. The mechanical properties of these materials are given in Table 1 [14].

Table 1. Mechanical properties of deep drawing steels.

\begin{tabular}{|c|c|c|c|c|}
\hline $\begin{array}{c}\text { Mechanical } \\
\text { Property }\end{array}$ & \multicolumn{4}{|c|}{ Material Type } \\
\hline & DC01 & DC04 & DD13 & DD14 \\
\hline $\begin{array}{c}\text { Yield Strength } \\
\text { [MPa] }\end{array}$ & 280 & 210 & $170-330$ & $170-310$ \\
\hline $\begin{array}{c}\text { Ultimate Ten- } \\
\text { sile Strength } \\
\text { [MPa] }\end{array}$ & 410 & 350 & 400 & 380 \\
\hline $\begin{array}{c}\text { Elongation } \\
\text { [\%] }\end{array}$ & 28 & 38 & 28 & 33 \\
\hline
\end{tabular}

The chemical composition of these steel materials are given in Table 2 [14].

Table 2. Chemical composition of deep drawing steel.

\begin{tabular}{|c|c|c|c|c|}
\hline $\begin{array}{c}\text { Material } \\
\text { Type }\end{array}$ & \multicolumn{4}{|c|}{ Chemical Composition } \\
\hline & C & Mn & P & S \\
\hline DC01 & 0,12 & 0,60 & 0,045 & 0,020 \\
\hline DC04 & 0,08 & 0,40 & 0,030 & 0,030 \\
\hline DD13 & 0,07 & 0,35 & 0,025 & 0,025 \\
\hline DD14 & 0,08 & 0,35 & 0,025 & 0,025 \\
\hline
\end{tabular}

Circular punch, die, blank holder and work piece in appropriate dimensions were produced in the solid modeling software and transferred to Simufact.forming software. Analyzes (Figure 2) were performed using a hydraulic press mechanism with a constant speed of $3 \mathrm{~mm} / \mathrm{s}$. Maximum effective stress, punch stroke, minimum sheet thickness, maximum molding force and total deformation energy data were obtained and compared with $40 \mathrm{kN}$ and $80 \mathrm{kN}$ blank holder forces under 0.02 and 0.10 friction coefficient parameters for each material.

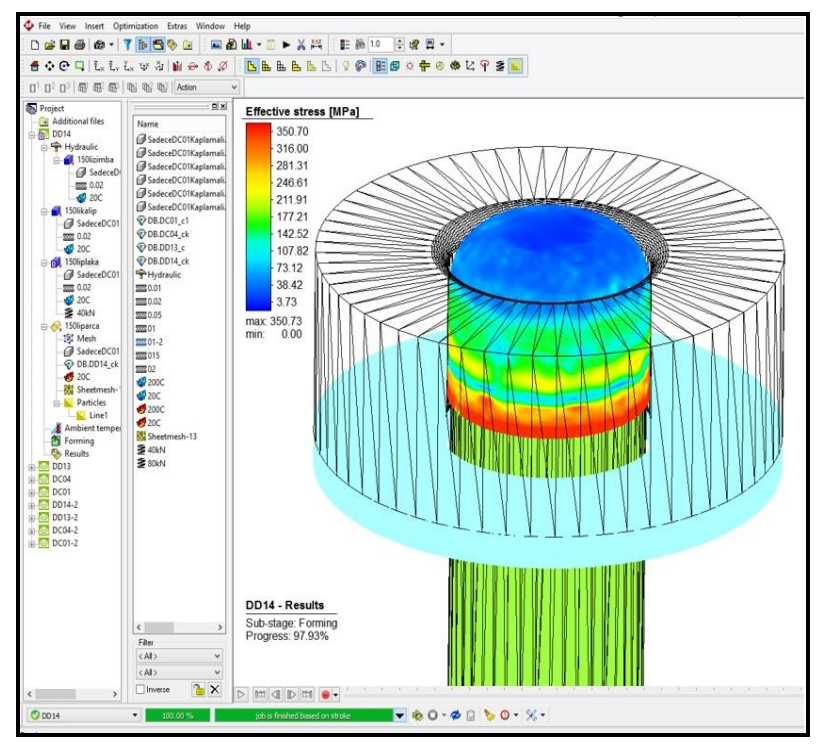

Fig. 2. A deep drawing analysis performed in the simulation software.

To obtain homogeneous blank holder pressure, the blank holder forces were applied to the workpiece via the blank holder using a compressed spring. The Coulomb friction model is very suitable for calculating the dry friction conditions, which mean contact between the friction parts without any intermediate layers [15]. For this reason, in the Simufact.forming software used in this study, Coulumb friction model was applied between sheet metal-mold and sheet metal-blank holder in the deep drawing process of four different steel sheets (Figure 3).

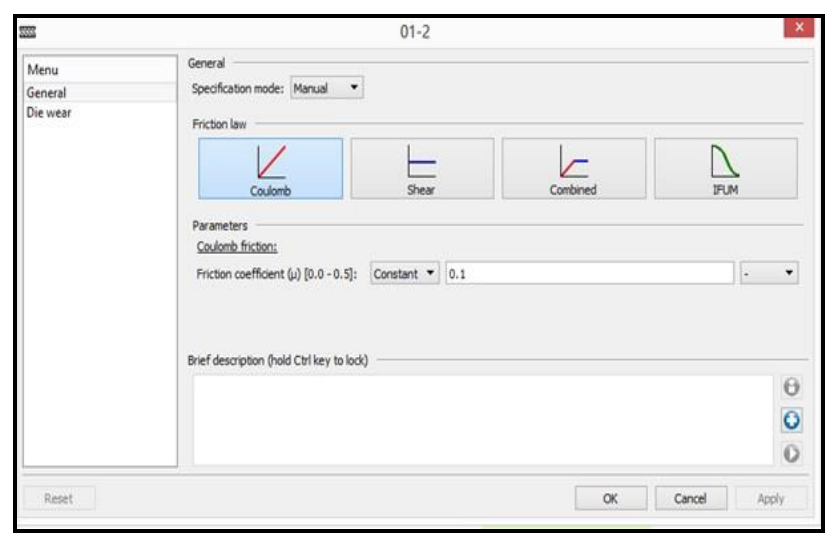

Fig. 3. Selection of the friction parameter in the simulation software.

Maximum effective stress, punch stroke, minimum sheet thickness, maximum molding force and total punch energy values obtained from the study results were compared by using different blank holder force and friction coefficient parameters. In order to make the graphics more comprehensible, the minimum sheet thickness is expressed as microm- 
eter $(\mu \mathrm{m})$ and the total punch energy is expressed by decajoule (daJ) units.

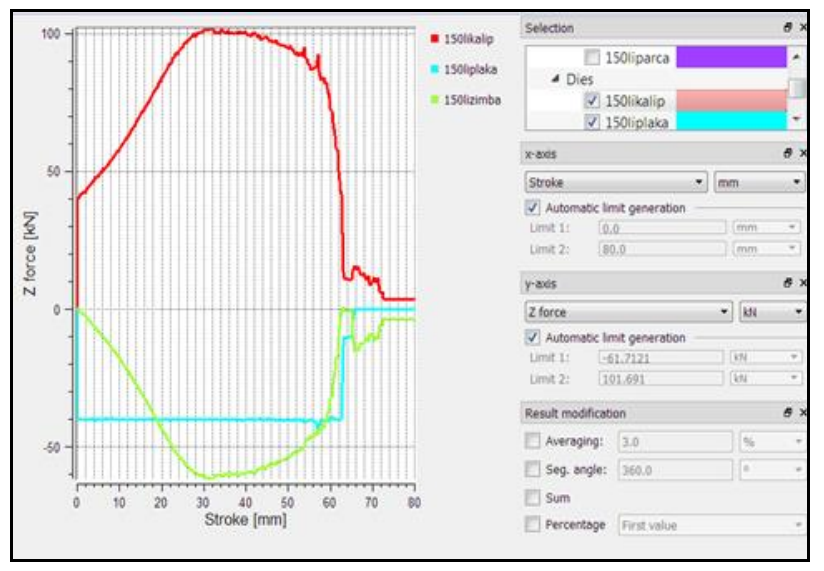

Fig. 4. Figure Molding force graphics

\section{Results}

When the blank holder force of $40 \mathrm{kN}$ was applied by selecting the coefficient of friction 0.1 , the lowest maximum effective stress value in the specimens was obtained in DD14 material with $333 \mathrm{MPa}$ and the highest maximum effective stress value was obtained in DC01 material with $607 \mathrm{MPa}$. When the friction coefficient was reduced to 0.02, the maximum effective stresses in DD14 and DC01 were reduced to $316 \mathrm{MPa}$ and $567 \mathrm{MPa}$, respectively. It has been observed that the stress values in both friction conditions have increased in a compatible manner when the blank holder force is $80 \mathrm{kN}$. Similarly, when the graphs (Figure 5-8) are examined, it is seen that the sorting of maximum effective stress, maximum molding force and total punch energy values for all materials do not change. Reducing the stresses due to the improvement of friction conditions during forming, reduces the required molding force and punch energy.

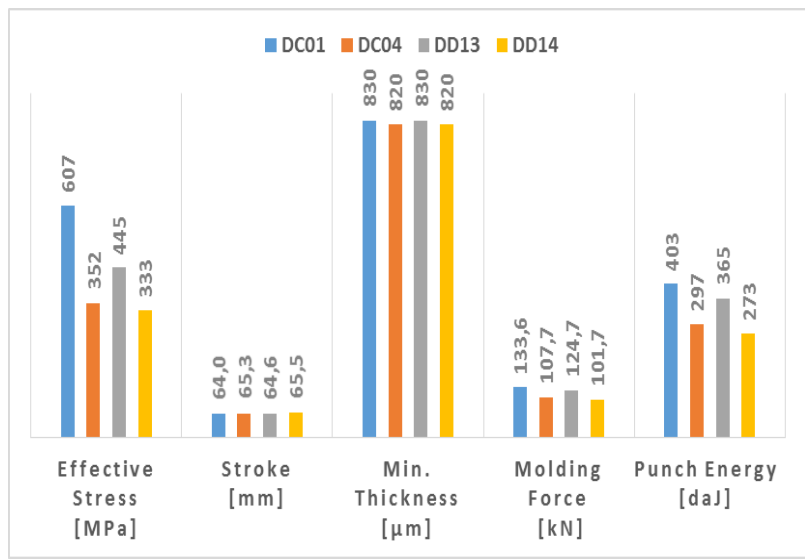

Fig. 5. Comparison of deep drawing results for $40 \mathrm{kN}$ blank holder force and 0.10 friction coefficient.
The lowest molding forces were observed in DD14 material under both blank holder force and friction conditions. However, the highest deep drawing height was also reached in this material.

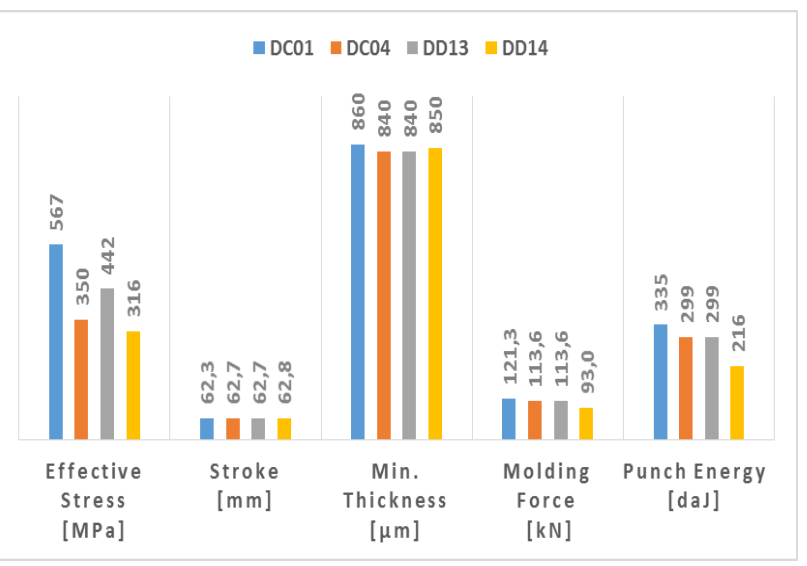

Fig. 6. Comparison of deep drawing results for $40 \mathrm{kN}$ blank holder force and 0.02 friction coefficient.

When friction is reduced to 0.02 compared to the experiments with $40 \mathrm{kN}$ blank holder force and 0.10 friction coefficient values; the DD14 material showed a 7\% reduction in the maximum effective stress value, while the DC01 material had a $9 \%$ reduction in the maximum molding force.

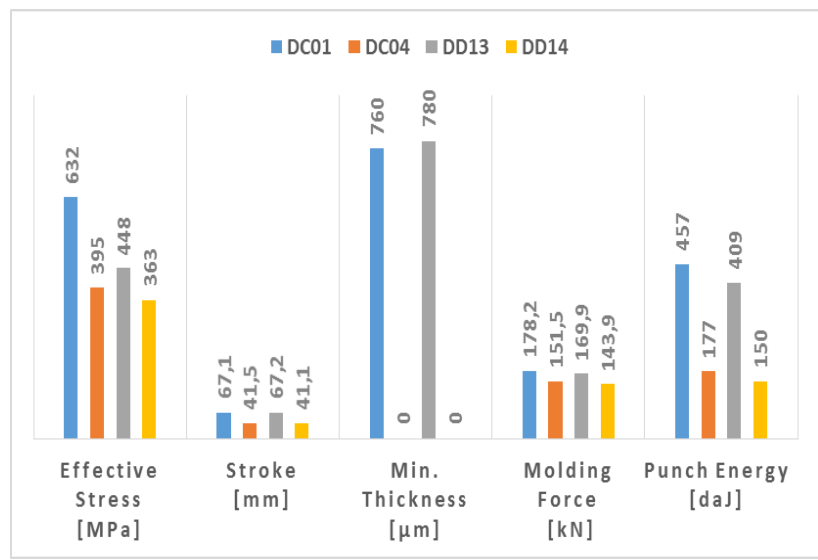

Fig. 7. Comparison of deep drawing results for $80 \mathrm{kN}$ blank holder force and 0.10 friction coefficient.

In the analyzes carried out with a blank holder force of $80 \mathrm{kN}$ and friction coefficient of 0.10 , deep drawing specimens of DC04 and DD14 were damaged due to tearing after about $41 \mathrm{~mm}$ punch stroke (Figure 7). Therefore, the minimum sheet thickness values of these samples were expressed as 0 in the graphs and the total punch energy values were very low as the deep drawing process could not be completed. 
By investigating the results of deep drawing analyzes of DC04 and DD14 materials with $80 \mathrm{kN}$ blank holder force, it is seen that specimens were damaged when the friction coefficient was high (0.10), while the process was completed successfully when the friction was reduced to 0.02 . In the light of these results, it is seen that friction conditions such as lubrication and roughness have a significant effect during deep drawing process. Also, it is clear that determination of blank holder force value affects the effectiveness of the process.

\section{References}

[1] Groover, M.P., (2016). Fundamentals of modern manufacturing: materials, processes, and systems, Sixth ed. John Wiley \& Sons, Inc., Hoboken, NJ.

Fig. 8. Comparison of deep drawing results for $80 \mathrm{kN}$ blank holder force and 0.02 friction coefficient.

When the blank holder force of $80 \mathrm{kN}$ was applied with a low coefficient of friction of 0.02 , the deep drawing specimens DC04 and DD14 were deep drawn properly without tearing (Figure 8). The minimum sheet thickness value increases by means of the more uniform distribution of the unit deformation in the work pieces, when the low friction coefficient is applied to both blank holder force values. In other words, the thickness distribution of the deep drawn product has been more homogeneous, resulting in reduced punch stroke and product height.

\section{Conclusions}

In this study, deep drawing analyzes of four different steel sheet materials, namely DC01, DC04, DD13 and DD14, which are widely used in deep drawing applications, were performed via finite element method in two different blank holder force and friction conditions. The maximum effective stress, punch stroke, minimum sheet thickness, maximum molding force and total punch energy values obtained from the analyzes were compared and significant differences were observed between the deep drawing behaviors of these materials. As a result of all analyzes, maximum effective stress and total punch energy values for DC01 material were maximum as seen from the graphs shown in Figure 5-8. This situation causes the deep drawing forces to be too high and increases the energy required to carry out the process.

When low blank holder forces are applied to DC04 and DD14 materials, it can be seen that higher deep drawing height can be obtained compared to other deep drawing materials.

[2] Vahdat, V., Santhanam, S., Chun, Y.W., (2006). A numerical investigation on the use of drawbeads to minimize ear formation in deep drawing. J Mater Process Tech 176.

[3] Yagami, T., Manabe, K., Yamauchi, Y., (2007). Effect of alternating blank holder motion of drawing and wrinkle elimination on deep-drawability. J Mater Process Tech 187, 187191.

[4] Sheng, Z.Q., Jirathearanat, S., Altan, T., (2004). Adaptive FEM simulation for prediction of variable blank holder force in conical cup drawing. International Journal of Machine Tools \& Manufacture $44,487-494$.

[5] Sokolova, O.A., Kühn, M., Palkowski, H., (2012). Deep drawing properties of lightweight steel/polymer/steel sandwich composites, Archives of civil and mechanical engineering 12,105-112.

[6] Yildiz, H., Kirli, O., (2004). Modeling of deep drawing by using non-linear finite element method, Journal of Engineering Sciences, 10, 3, 317-326.

[7] Mori, K., Tjusi, H., (2007). Cold deep drawing of commercial magnesium alloy sheets, Annals of the CIRP, 56: 285288.

[8] Browne M.T., Hillery M.T., (2003). Optimising the variables when deep-drawing CR1 cups. J Mater Process Tech 136 (1-3):64-71.

[9] Admanabhan, R., Oliveira M.C., Alves J.L., Menezes L.F., (2008). An optimization strategy forthe blankholder force in deep drawing, 8th World Congress on Computational Mechanics, Venice-Italy.

[10] Gok, A, (2007). Application of the finite element method to the deep drawing process and analysis with a real industrial part, Master of Science, Afyon Kocatepe University.

[11] Chengzhi, S., Guanlong, C., Zhongqin, L., (2005). Determining the optimum variable blank-holder forces using adaptive response surface methodology (ARSM). Int $J$ Adv Manuf Tech 26, 23-29.

[12] Kitayama, S., Natsume, S., Yamazaki, K., Han, J., Uchida, H., (2016). Numerical investigation and optimization of pulsating and variable blank holder force for identification of 
formability window for deep drawing of cylindrical cup. Int J Adv Manuf Tech 82, 583-593.

[13] Demirci, H.I., Yasar M., Demiray K., Karali M., (2008). The Theoretical and experimental investigation of blank holder forces plate effect in deep drawing process of $\mathrm{AL}$ 1050 materials, Materials \&Design, 29, 526-532.

[14] Anonymous, (2017). Erdemir Sheet Metal Catalog. Ereğli Iron and Steel Factory.

[15] MSC Software Corporation, (2015). Simufact.forming 14.0, Izmir. 